\title{
Community psychiatry: weasel words?
}

\section{A personal view}

\author{
J.A. Robertson
}

The practice of modern high quality psychiatry would be well served by the abandonment of the expression 'community psychiatry' and a moratorium on its further use for at least a decade.

This statement clearly needs explication and defence, so I will try to explain. For nearly 20 years I have been involved with a project devoted to the replacement of an old county institution with a network of local, accessible and appropriate services. The enterprise has been on the whole successful and, as I write, the first blows of the demolition hammer are falling on the old asylum buildings which have lain empty for several years. Their functions have been replaced by a dispersed network of services shared between the health service and local social services.

I am aware that many districts have been waiting for years for a similar realignment of services, only to have plan after plan rejected or stripped down to an unworkable level. All too often this is done in the name of 'community psychiatry' or 'care in the community'. What started as an ideal has become an excuse for buck-passing, asset stripping and skimping on provision. There seems to be an irresistible slippage from the position that psychiatric services are best provided outside hospital to the belief that specialist secondary care services are redundant. This needs to be set in the wider context of the government's rapid but stealthy retreat from universal free health care provision within the NHS to the farming out of virtually everything apart from acute treatment to other settings, where it is subject to a form of means testing.

This is not just psychiatry's problem. The rhetoric of 'community' as adjective or noun bedevils a whole range of services. It is often allied with other seductive concepts such as 'prevention ' and 'health promotion'. The future of health services is seen to lie in a fusion of these ideas with the energies of the primary health team, leading to the relative eclipse of the secondary care services based in hospitals. This is despite the fact that primary care workers such as GPs continue to rely heavily on their specialist colleagues whose base of beds and other resources is fast being eroded.

Psychiatrists, at least in the UK, have been socially minded for many years and have been critically debating concepts such as prevention for a long time. Much of the drive towards the closure of inappropriate institutions has come from within their ranks, despite the importance of sociological contributions such as those of Goffman. Psychiatric epidemiologists have shown that the great mass of psychiatric morbidity is indeed to be found in the population at large rather than in hospitals and that most of it is managed by GPs.

At the other extreme, that of major mental illness, pioneering projects in acute home treatment have been conducted and evaluated by clinicians. The implications of all these developments have been eagerly embraced by planners in so far as they seem to justify the run-down of hospital services for mental illness. What they consistently ignore is the evidence that not all psychiatric illness can be managed in the community'. A small number of patients need longterm psychiatric nursing with specialist medical oversight and a larger number need specialist management in their normal environment.

It has been pointed out by Sartorius among others that the English word 'community' embraced two concepts which German sociologists describe separately as Gemeinschaft and Gesellscaft. The former implies an organic whole which has cultural coherence, the latter simply a collection of people sharing the same geographical space. Clearly the 'sociological-pastoral' Ideal can only be attached to 'community' in the first sense and if there is indeed an entity which can 'care' in any meaningful way that must be it. However, not only is 'community' more commonly used in the latter sense (which is at least more realistic) it is used in psychiatric contexts to mean a whole range of other things: treatment outside traditional mental hospitals, treatment in general hospitals, treatment at home, 
treatment in mental health resource centres, by 'community mental health teams' by primary health care teams and in health centres. Add to this the artificial distinction between 'treatment' and 'care' and the picture becomes even more confusing - at least in the contemporary British context. For 'community' and 'care' have not only become paired but inextricably associated with progressive practice. This might not matter if recent legislation had not handed lead responsibility for community care squarely to local social services departments whose record over the past 20 years in this regard has generally been lamentable. Even more disastrously, it has handed NHS managers, invariably hard-pressed financially, an excuse for paring psychiatric facilities to the bone. The situation in the inner cities is widely agreed to be scandalous and we shall be lucky if smaller towns and rural areas escape their fate as cuts bite deeper. If present trends are any guide, every reduction in service will be heralded by a flurry of rhetoric about redevelopment towards a more community oriented service. Every step towards anarchy and neglect is heralded as a step towards Utopia.

Did we ever dream, as we marched out of the asylums, that a few miles down the road we would have lost so much - budgets, integrated teams, expertise, facilities and morale - in the name of 'community psychiatry'? But it is our patients who will be the real losers if they are either neglected in the pseudo-community or re-institutionalised as a result of public backlash.

Ideally, we need a unified mental illness service which embraces treatment, rehabilitation and care across a whole range of settings, respecting the principle of the least restrictive environment. It does patients no good to have to cross an organisational, financial and ideological divide every time they move from a 'hospital' to a 'community' setting. A variety of professional disciplines and values could be represented within such a system and if there were fears for patients' liberties in too monolithic an organisation, an independent advocacy system would be sufficient to protect them.

Perhaps this is too much to hope for. Suspicion of the 'medical model' is too widespread and the gulf between health and social services has become an accepted feature of the landscape which is rarely questioned. Nevertheless, we might go some way towards halting the destruction of services and planning their repair in a clear headed way if the hollow cant of 'community psychiatry' was entirely abandoned.

J.A. Robertson, Consultant Psychiatrist, Kidderminster General Hospital, Bewdley Road, Kidderminster, Worcestershire DY11 6RJ 